\title{
AN ASSESSMENT OF RECOVSAT UTILIZATION FOR DIFFERENT SERVICE TYPOLOGIES
}

\author{
ANA CRISTINA COSTA, ROGÉRIO PUGA-LEAL, \\ ZULEMA LOPES PEREIRA
}

\section{INTRODUCTION}

It is broadly accepted that customer's demands are continuously increasing (e.g. Behara and Gundersen, 2001). As a consequence, organizations are often exposed to a cycle of severity (Puga-Leal and Pereira, 2003) such as represented in Figure 1.

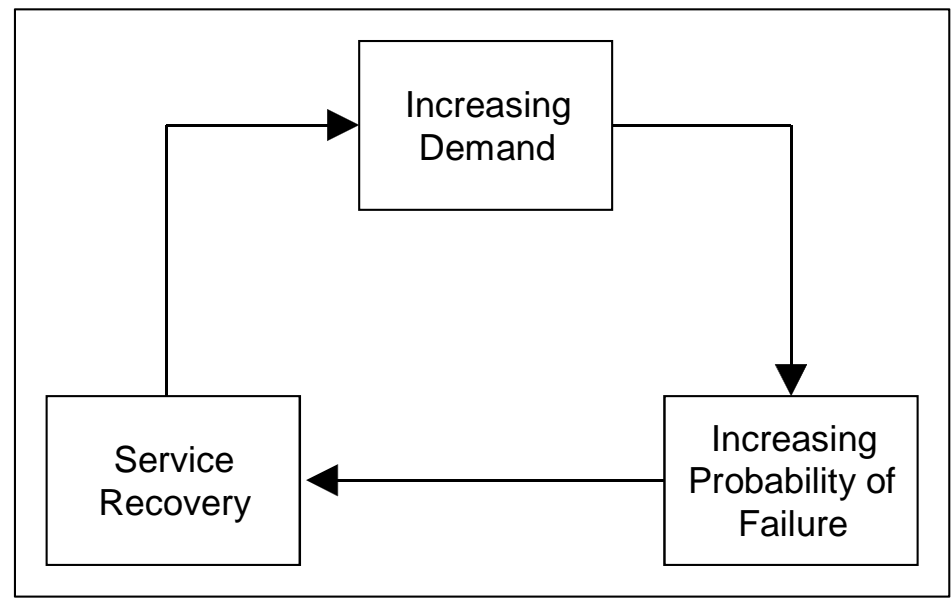

Figure 1-Cycle of Severity

Increased demand induces an increased probability of failure, thus originating the need for service recovery. Furthermore, as stressed by Evardsson et al. (2011), poor recovery processes are very often experienced by customers, which worsens the overall situation.

Boshoff (1997) referred to service recovery as the component of quality management that can maintain the business relationship with customers. Tax and Brown (2000) defined service recovery as a process oriented towards the identification of service failure, resolution of customer's problems, identification of root causes and improvement of the service system. Boshoff (2005a) noted that service recovery can occur during service delivery or after complaining, and can be associated to a specific transaction as well as to the relationship among parts. More recently, Michel et al. (2009) broadened the notion of service 
recovery encompassing three different perspectives: customer recovery, process recovery and employee recovery.

For a long time, service recovery was an area often neglected (Andreassen, 1999). However, a lot of valuable insights have been produced in the last years. Far from being exhaustive, Evardsson et al. (2011) addressed the issue of triple deviation in complex service recovery processes. Wirtz and Matilla (2004) studied consumer responses to compensation, speed of recovery and apology after a service failure. Rio-Lanza et al. (2009) examined the relationship between perceived justice, emotions and satisfaction during service recovery. Rogeveen et al. (2011) focused their attention on co-creation effect in service recovery and Kim et al. (2010) studied the relationship between consumer complaining behavior and service recovery.

Several other developments could have been referred to, but it is worth mentioning the publication of Bolton et al. (2007) that includes planning for service recovery in the agenda for future research among the strategies for competing through service. In fact, as pointed out by Krishna et al. (2011), service recovery research calls serious attention in the present time.

Table 1 - Adjusted Recovsat model

\begin{tabular}{|c|c|}
\hline \multirow{3}{*}{ Compensation } & Company Compensated for financial loss \\
\hline & Compensation was fair \\
\hline & Customer was satisfied with given compensation \\
\hline \multirow{4}{*}{ Communication } & Communication was clear \\
\hline & Questions were asked to clarify the situation \\
\hline & Employee was polite \\
\hline & Employee was understanding \\
\hline \multirow{3}{*}{ Empowerment } & First contacted employee solved the problem \\
\hline & Employee did not need help to solve problem \\
\hline & Employee did not pass the problem on to someone else \\
\hline \multirow{3}{*}{ Timely feedback } & Company gave feedback \\
\hline & Didn't take long before company contacted customer \\
\hline & Problem was solved within a reasonable time \\
\hline \multirow{2}{*}{ Tangibles } & Company made appropriate use of medium \\
\hline & Medium used for communication appeared professional \\
\hline \multirow{2}{*}{ Apologies } & Company apologized for situation \\
\hline & Company apologized for financial loss \\
\hline \multirow{2}{*}{ Explanation } & Company gave an explanation for situation \\
\hline & Company gave satisfactory explanation for situation \\
\hline
\end{tabular}




\section{RECOVSAT}

Recovsat was originally proposed by Boshoff (1999) as an instrument to measure customer satisfaction with service recovery. This instrument was based on the assumption that service recovery is a multidimensional construct. The original six dimensions captured by Recovsat were Communication, Empowerment, Feedback, Atonement, Explanation and Tangibles. Later, Boshoff (2005a) produced a re-assessment and refinement of Recovsat instrument, based on a survey of bank clients "who have lodged complaints with a retail bank".

After that, in a new publication, a further adaptation was made in Recovsat (Boshoff et al., 2005b). A time dimension was added, transforming the original "Feedback" dimension into "Timely Feedback". Furthermore, the original "Atonement" dimension was split in two separate dimensions: "Apology" and "Compensation". Therefore, the adjusted Recovsat model that was used in this piece of research includes seven dimensions (Compensation, Communication, Empowerment, Timely feedback, Tangibles, Apologies and Explanation) comprising nineteen items (Table 1).

\section{PURPOSE AND METHODOLOGY}

The main purpose of the study was to evaluate how well the dimensional structure of Recovsat is replicated when the instrument is applied to a combination of different service typologies. The adopted typologies were based on the Silvestro et al. (1992) classification that establishes three service archetypes:

1) Professional services: "organizations with relatively few transactions, highly customized, process oriented, with relatively long contact time, with most value added in the front office, where considerable judgment is applied in meeting customer needs";

2) Mass services: "organizations where there are many customer transactions, involving limited contact time and little customization. The offering is predominantly product-oriented with most value being added in the back office and little judgment applied by the front office staff";

3) Service shops: "a categorization which falls between professional and mass services with the levels of classification dimensions falling between the other two extremes".

The impact of the factors that emerged from the Factor Analysis on overall satisfaction (OS), intention to repurchase (IR) and recommendation (R) was also studied. As such, the study contemplated three main stages. The first stage included a descriptive analysis of the incidence and consequences of complaints in several categories of services. A Factor Analysis was performed in the second 
stage to compare the factor structure that emerged from the obtained data with that proposed by Recovsat. Finally, several regression models were used in the last stage to assess the influence of service recovery on the overall satisfaction, intention to repurchase and recommendation.

\section{SAMPLE CHARACTERIZATION}

The study was based on a convenience sample of individuals that were available to fill the Recovsat questionnaire, along with some other questions regarding the targeted service, the overall satisfaction, the intention to repurchase and the willingness to recommend the service.

A sample of 110 respondents was obtained. Most of the situations were associated to mass services (76\%) and occurred in the six months (53\%) anteceding the questionnaire administration.

It is worth mentioning that, in $42 \%$ of situations, a solution was proposed to the complaining customer in less than a week. However, $24 \%$ of customers referred that an acceptable solution was never achieved.

The relationships between service typology and the variables "overall satisfaction", "intention to repurchase" and "recommendation" were also analyzed. The results are presented in tables 2, 3 and 4 .

Table 2 - Service typology vs Overall satisfaction

\begin{tabular}{|c|c|c|c|c|}
\cline { 3 - 5 } \multicolumn{2}{c|}{} & \multicolumn{3}{c|}{ Overall satisfaction } \\
\cline { 3 - 5 } \multicolumn{2}{c|}{} & Dissatisfied & Neutral & Satisfied \\
\hline \multirow{3}{*}{\begin{tabular}{c}
$n y y y$ \\
\cline { 1 - 4 }
\end{tabular}} & Mass services & $40.5 \%$ & $20.2 \%$ & $39.3 \%$ \\
\cline { 2 - 5 } & Professional Services & $33.3 \%$ & $22.3 \%$ & $44.4 \%$ \\
\cline { 2 - 5 } & Service shop & $52.9 \%$ & $23.5 \%$ & $23.6 \%$ \\
\hline
\end{tabular}

Table 3 - Service typology vs Intention to repurchase

\begin{tabular}{|c|c|c|c|c|}
\hline & \multicolumn{3}{|c|}{ Intention to repurchase } \\
\hline & & No & Neutral & Yes \\
\hline \multirow{3}{*}{ : } & Mass services & $27.4 \%$ & $16.6 \%$ & $56.0 \%$ \\
\hline & Professional Services & $33.3 \%$ & $0.0 \%$ & $66.7 \%$ \\
\hline & Service shop & $52.9 \%$ & $17.6 \%$ & $29.5 \%$ \\
\hline
\end{tabular}


Table 4 - Service typology vs Recommendation

\begin{tabular}{|c|c|c|c|c|}
\hline & \multicolumn{3}{|c|}{ Recommendation } \\
\hline & & $\begin{array}{c}\text { Non- } \\
\text { recommendation } \\
\end{array}$ & Neutral & Recommend \\
\hline \multirow{3}{*}{ 总 } & Mass services & $42.9 \%$ & $15.5 \%$ & $41.6 \%$ \\
\hline & Professional Services & $55.6 \%$ & $0.0 \%$ & $44.4 \%$ \\
\hline & Service shop & $45.4 \%$ & $15.5 \%$ & $39.1 \%$ \\
\hline
\end{tabular}

A few conclusions appear to be clear. Service shops are the most penalized as regards intention to repurchase as well as regards overall satisfaction. However, it must be noticed that a non-recommendation behavior after a dissatisfaction episode prevails in all service typologies, which constitutes an important alert for decision makers.

\section{FACTOR STRUCTURE}

As mentioned before, factor analysis was performed to obtain a factors structure that could be compared to the one proposed in the Recovsat instrument.

Principal component analysis was utilized as extraction method and varimax was adopted for factors' rotation.

KMO measure was equal to 0.887 , which reveals a good sampling adequacy. According to sample size, only factor loadings above 0.50 must be considered (Hair et al., 1995). The rotated component matrix, including factor loadings over 0.50 , is presented in table 5 . With an exception for tangibles 1 , communalities ranged from 0.653 (explanation1) to 0.948 (communication2). Tangibles1 obtained a communality of 0.458 and constituted a problem in the research, since it could not be allocated to any factor. Further research must be developed to confirm it, but the authors do not exclude that item's translation might not have been fully understood by respondents.

It can be seen that Factor 1 includes all the items associated to "Communication", along with item tangibles2. However, tangibles2 regards the "medium used for communication", seeming reasonable that respondents associate this item with those focused on communication characteristics.

Factor 3 includes all the items associated with "Compensation", thus reflecting a perfect alignment with Recovsat. 
Table 5 - Rotated Component Matrix

\begin{tabular}{|c|c|c|c|c|}
\hline & \multicolumn{4}{|c|}{ Factor } \\
\hline & 1 & 2 & 3 & 4 \\
\hline Communication3 & .903 & & & \\
\hline Communication4 & .897 & & & \\
\hline Communication1 & .807 & & & \\
\hline Communication2 & .771 & & & \\
\hline Tangibles2 & .696 & & & \\
\hline Apology1 & & .868 & & \\
\hline Apoology2 & & .791 & & \\
\hline Explanation2 & & .709 & & \\
\hline Explanation 1 & & .689 & & \\
\hline Timelyfeedback1 & & .646 & & \\
\hline Timelyfeedback2 & & .617 & & \\
\hline Compensation1 & & & .914 & \\
\hline Compensation 2 & & & .909 & \\
\hline Compensation3 & & & .862 & \\
\hline Tangibles1 & & & & \\
\hline Empowerment 2 & & & & .822 \\
\hline Empowerment 3 & & & & .786 \\
\hline Empowerment 1 & & & & .707 \\
\hline Timelyfeedback3 & & & & .656 \\
\hline
\end{tabular}

Factor 4 includes all the items regarding "Empowerment", along with item timelyfeedback3. This item is focused on time to solve the problem, whose association with empowerment is meaningful. In fact, when empowerment policies are in place, problems are usually quicker to solve. Besides, although this interpretation can be controversial, it is authors' conviction that a time dimension is in customers' mind when answering these questions. In fact, empowerment is a consequence of company's policy and it is not relevant from the customer's perspective. On the other hand, the consequence of such empowerment is the timely resolution of complaints, which the authors believe it is implicit in the Recovsat questions. Therefore, it was decided to adopt the expression "Timely resolution" to characterize this factor.

Interpreting Factor 2 is not straightforward. This factor includes the items regarding "Apologies", "Explanation" and "Timely feedback". As it can be seen in table 1, all these items regard an adequate interaction between complaining customers and service provider. Therefore, "Empathy" seems to be an adequate definition to characterize the factor.

Reliability was computed for each of these factors, and excellent values were obtained as presented in Table 6 . 
Table 6 - Reliability for each factor

\begin{tabular}{|c|c|c|c|c|}
\cline { 2 - 5 } \multicolumn{1}{c|}{} & Communication & Empathy & Compensation & Timely resolution \\
\hline Alpha & 0.928 & 0.916 & 0.977 & 0.877 \\
\hline
\end{tabular}

It is important to note that removing any item would contribute for a lower reliability in the corresponding factor.

\section{MULTIPLE REGRESSION MODELS}

Several regression models were developed to assess the impact of service recovery's factors on overall satisfaction (OS), intention to repurchase (IR) and recommendation $(\mathrm{R})$.

Surrogate variables were used in multiple regression models. As stated by Hair et al. (1995), the researcher could examine the factor matrix and select the variable with the highest factor loading on each factor as a surrogate representative for that particular factor. According to this procedure, the following variables were selected: communication 3 , apologyl, compensation 1 and empowerment2. Table 7 presents a summary of obtained results.

Table 7 - Multiple regression models

\begin{tabular}{|c|c|c|c|c|c|}
\hline & & Communication & Empathy & Compensation & $\begin{array}{c}\text { Timely } \\
\text { resolution }\end{array}$ \\
\hline & R-square & \multicolumn{4}{|c|}{ Standardized regression coefficients } \\
\hline$\overline{\mathrm{OS}}$ & 0.660 & 0.234 & 0.271 & 0.425 & 0.226 \\
\hline IR & 0.489 & 0.263 & - & 0.457 & 0.256 \\
\hline $\mathbf{R}$ & 0.496 & - & 0.227 & 0.391 & 0.337 \\
\hline
\end{tabular}

It is relevant noticing that the factor "Compensation" is consistently the one with larger regression coefficients. Therefore, regardless other actions, decision makers must be aware that compensating customers plays a major role in overall satisfaction with service recovery, as well as in repurchase intentions and willingness to recommend the service. Furthermore, it is also worth mentioning "Timely feedback" (or "Empowerment", from the original Recovsat perspective) is also significant for the several models.

\section{CONCLUSION}

Service performances that fail to meet customer expectations will always occur, which implies that adequate service recoveries have to be in place.

Recovsat constitutes an important contribution as an instrument to measure customer satisfaction with service recovery. 
Nevertheless, failure modes in services can be quite heterogeneous, as well as their consequences. In fact, they can correspond to inadequate human behavior, delays, poor performance, financial loss, etc.. Thus, it seemed interesting to assess how well the factor structure of Recovsat could be replicated in a sample of complaining customers, covering a range of different service typologies.

After factor rotation, it was concluded that items from the same dimension in the original Recovsat scale tend to be kept together in the new structure. However, items regarding "Apology" and "Explanation" were merged into the same dimension, along with timelyfeedbackl ("company gave feedback") and timelyfeedback2 ("didn't take long before company contacted customer"). It was authors' opinion that all these items were associated to the interaction between complaining customers and service provider, and "Empathy" would be the underlying dimension. Furthermore, timelyfeedback3 was merged with "Empowerment" items. The authors' interpretation was that all these items represent "Timely feedback" in customers" mind. Somehow supporting this perspective, it is interesting to note that original "Empowerment" dimension was never a significant variable in the regression models performed by Boshoff et al. (2005b).

As a corollary, the authors believe that a structure with only four dimensions might be more adequate to represent a large spectrum of service typologies. Under TQM (Total Quality Management) perspective, these dimensions correspond to a balance between hard (Compensation and Timely resolution) and soft (Communication and Empathy) characteristics.

As regards the regression models, "Compensation" proved to be the most significant dimension for all the dependent variables (Overall satisfaction, Intention to repurchase and Recommendation). However, it should be noted that these are global results since the sample size was not large enough to be split in order to support a stratified analysis.

The importance of "Compensation" is also reflected in Boshoff et al. (2005b) conclusions and partially by Wirtz and Matilla (2004) who concluded that compensation was effective in increasing satisfaction in mixed-bag recovery process. Grewal et al. (2008) concluded that compensation enhances repurchase intentions when the company is responsible for the failure.

Taking into account the proposed distinction between hard and soft characteristics, it is concluded that hard characteristics are globally more important as regards the studied sample. Nevertheless, it is authors' conviction that both the complaining behavior and the recovery perceptions are strongly affected by cultural characteristics, which requires caution when generalizing results.

\section{Limitations and suggestions for future research}

The data were obtained from a convenience sample, thus imposing restrictions to the generalization of the results. 
The comparison of service recovery characteristics and the corresponding customer perceptions, across countries and service typologies, is an interesting challenge that remains largely unexplored.

\section{REFERENCES}

Andreassen, T.W. (1999), "What drives customer loyalty with complaint resolution?”, Journal of Service Research, Vol. 1, No. 4, pp. 324-32.

Behara, R.S. and Gundersen, D.E. (2001), "Analysis of quality management practices in services", International Journal of Quality \& Reliability Management, Vol. 18, No. 6, pp. 584-603.

Bolton, R., Grewal, D. and Levy, M., (2007), "Six strategies for competing through service: An agenda for future research", Journal of Retailing, 83 (1), pp. 1-4.

Boshoff, C. (1997), "An experimental study of service recovery options", International Journal of Service Industry Management, Vol. 7, No. 5, pp. 32-46.

Boshoff, C., (1999), "An instrument to measure satisfaction with transactionspecific service recovery", Journal of service research, Vol. 1, No. 3, pp. 236249.

Boshoff, C., (2005a), "A re-assessment and refinement of RECOVSAT", Managing service quality, Vol. 15, No. 5, pp. 410-425.

Boshoff, C., Peelen, E., Hoogendoorn, M. e Kraan, Y. (2005b), “A differentiated approach to service recovery", NRG working paper series, No. 05-03, pp. 1-10.

Edvardsson, B., Tronvoll, B. and Höykinpuro, R. (2011), "Complex service recovery processes: how to avoid triple deviation", Managing Service Quality, Vol. 21, Iss: 4, pp. $331-349$.

Grewal, D., Roggeveen, A. and Tsiros, M. (2008), "The Effect of Compensation on Repurchase Intentions in Service Recovery", Journal of Retailing, 84 (4), pp. 424-434.

Hair, J., Anderson, R., Tatham, R. and Black, W. (1995), Multivariate data analysis, $4^{\text {th }} \mathrm{Ed}$, Pearson Prentice Hall, New Jersey.

Kim, M. G., Wang C. and Mattila A. S. (2010), "The relationship between consumer complaining behavior and service recovery", International Journal of Contemporary Hospitality Management, Vol. 22, No. 7, pp. 975-991.

Krishna, A., Dangayach, G. and Jain, R. (2011), "Service Recovery: Literature Review and Research Issues", Journal of Service Science Research, Vol. 3, Iss: 1, pp. 71-121, DOI 10.1007/s12927-011-0004-8.

Michel, S., Bowen, D. and Johnston, R. (2009), "Why service recovery fails: Tensions among customer, employee, and process perspectives", Journal of Service Management, Vol. 20, Iss: 3, pp. 253 - 273. 
Puga-Leal, R. and Pereira, Z. (2003), "Service recovery at a financial institution", International Journal of Quality \& Reliability Management, Vol. 20, No. 6, pp. 646-63.

Río-Lanza, A., Vázquez-Casielles, R. and Díaz-Martín, A.(2009), "Satisfaction with service recovery: Perceived justice and emotional responses", Journal of Business Research, Vol. 62, Iss: 8, pp. 775-781.

Roggeveen, A., Tsiros, M.and Grewal, D., (2011), "Understanding the cocreation effect: when does collaborating with customers provide a lift to service recovery?", Journal of the Academy of Marketing Science, (13 August 2011), pp. 771-720, DOI: 10.1007/s11747-011-0274-1.

Silvestro, R., Fitzgerald, L. e Johnston, R. (1992), "Towards a classification of service processes", International journal of service industry management, Vol. 3, No. 3, pp. 62-75.

Tax, S. and Brown, S. (2000), "Service recovery: research insights and practices", in Swartz, T. and Iacobucci, D. (Eds), Handbook of Services Marketing and Management, Sage Publications, Thousand Oaks, CA.

Wirtz, J. and Mattila, A. (2004), "Consumer responses to compensation, speed of recovery and apology after a service failure", International Journal of Service Industry Management, Vol. 15, Iss: 2, pp. 150 - 166.

\section{ABOUT THE AUTHORS}

Ana Cristina Costa (anaccosta85@gmail.com) holds a master degree in Industrial Engineering and Management from Universidade Nova de Lisboa. She is currently a trainee at a car manufacturing company.

Rogério Puga-Leal (rpl@ fct.unl.pt) holds a PhD in Industrial Engineering from Universidade Nova de Lisboa. Currently he is an assistant professor at the Faculty of Science and Technology of Universidade Nova de Lisboa as well as coordinator of the Master program in Industrial Engineering and Management. $\mathrm{He}$ is a researcher at UNIDEMI - R\&D Unit in Mechanical and Industrial Engineering.

Zulema Lopes Pereira (zlp@fct.unl.pt) holds a PhD in Production Engineering from the University of Birmingham (UK). Currently she is full professor and vice-dean at the Faculty of Science and Technology of Universidade Nova de Lisboa. She is a researcher at UNIDEMI - R\&D Unit in Mechanical and Industrial Engineering. 